\title{
Piloting Computer Science Education Week in Mexico
}

\author{
Nora A. Escherle \\ School of Education \\ University of Applied Sciences \\ Northwestern Switzerland (FHNW) \\ Windisch, Switzerland \\ nora.escherle@fhnw.ch
}

\author{
Dorit Assaf \\ School of Education \\ University of Applied Sciences \\ Northwestern Switzerland (FHNW) \\ Windisch, Switzerland \\ dorit.assaf@fhnw.ch
}

\author{
Silvia I. Ramirez-Ramirez \\ Department of Computer Sciences \\ Tecnológico de Monterrey - \\ Campus Monterrey \\ Monterrey, Mexico \\ iliana.ramirez@itesm.mx
}

Ashok R. Basawapatna*

Department of Mathematics, Computer

\& Information Science

SUNY, Old Westbury

Old Westbury, NY 11568

basawapatnaa@oldwestbury.edu

\author{
Yasko Ch. Endo \\ Department of Computer Science \\ University of Colorado - Boulder \\ Boulder, CO 8030 \\ yasko.endo@colorado.edu
}

Alexander Repenning ${ }^{\S}$

School of Education

University of Applied Sciences,

Northwestern Switzerland (FHNW)

Windisch, Switzerland

alexander.repenning@fhnw.ch

\author{
Carmine Maiello \\ School of Education \\ University of Applied Sciences \\ Northwestern Switzerland (FHNW) \\ Windisch, Switzerland \\ carmine.maiello@fhnw.ch
}

\author{
Juan A. Nolazco-Florez \\ Department of Computer Sciences \\ Tecnológico de Monterrey \\ Monterrey, Mexico \\ jnolazco@itesm.mx
}

\begin{abstract}
programming tools embedded with tutorials, report large participation numbers. However, to truly broaden participation, activities need to be made accessible in international contexts. In 2014, Tecnológico de Monterrey and Instituto de Innovación y Transferencia de Tecnología de Nuevo León, modified the Scalable Game Design CS Ed Week activity to include a Mexican feasibility pilot study. The goal of the pilot was to broaden participation in Computer Science in Mexico by creating interest and demand in further activities, including launching of 2015 Mexico CS Ed Week. This paper reviews the initial results of this 2014 pilot, including the discussion of the unique challenges faced in this context, and examines efforts to make this activity more accessible and successful. In addition to pilot data highlighting future activity improvements, initial retention results show that despite challenges, Mexican students were able to effectively use the modified activity to create games on par with U.S. students.
\end{abstract}

\section{Keywords}

Broadening Participation; Computer Science Education; International Research; Computer Science Education in Mexico; Computer Science Education Week; Experience Report; Globalization of Programming Activities.

\section{INTRODUCTION}

Thanks to many reforms and initiatives in the sector of education, Mexico achieved a school enrollment of $94 \%$ of all children

\footnotetext{
${ }^{1 *}$ Additionally affiliated to the Dept. of CS, Univ. of Colorado - Boulder

${ }^{\S}$ Additionally affiliated to the School of Education, FHNW

Permission to make digital or hard copies of all or part of this work for personal or classroom use is granted without fee provided that copies are not made or distributed for profit or commercial advantage and that copies bear this notice and the full citation on the first page. Copyrights for components of this work owned by others than ACM must be honored. Abstracting with credit is permitted. To copy otherwise, or republish, to post on servers or to redistribute to lists, requires prior specific permission and/or a fee. Request permissions from Permissions@acm.org.

SIGCSE '16, March 2-5, 2016, Memphis, TN, USA

(C) 2016 ACM. ISBN 978-1-4503-3685-7/16/03 ..\$15.00

DOI: http://dx.doi.org/10.1145/2839509.2844598
}

Computer Science Education Week activities, featuring online between age 6 and 14 by 2010. However, according to the 2012 OCDE Education Report on Mexico, drop out rates are alarmingly high [14]. The transition to high school and further education shows a dropout rate of $43 \%$ for students between 15 and 19 [5]. Among the reasons to drop out school are poverty, ethnic inequality and gender. Dropout rates are far higher than in the United States, where in 2013 an average of $6.8 \%$ of all students dropout of high school before graduation [12].

Regarding students' access to ICT (Information and Communication Technologies) and the status of computer science education in Mexico, numbers are even worse. According to Martínez (2012), only $42.3 \%$ of the public schools at the elementary level have been equipped with computers, while only $18 \%$ have access to the Internet [10]. Again, this is in stark contrast to $97 \%$ of USA's public elementary schools having Internet connectivity at some level [11]. Furthermore, in Mexico the educative resources are not evenly distributed among schools, as the OCDE's quality index evidence shows Mexico to have the largest variances [14].

For several years now, many initiatives and reforms have been undertaken to improve the education system in Mexico [20]. An essential part of these envisioned improvements are efforts to effect the massive integration of ICT into basic education [19] because increased digital literacy and guaranteed access to ICT are considered vital to students' education and future careers. In order to effect these improvements in the field of ICT, educational reforms and programs have been launched by the state government and by institutions like universities and nongovernmental organizations. A main goal of programs such as Enciclomedia or Digital Abilities for Everyone (known in Spanish as HDT) was to mitigate the gross lack in technology infrastructure and equip schools with computers and software. Enciclomedia began to distribute computers to public schools from 1st to 9th grade in 2004 [20]. The program was interrupted, however, when some studies showed that the technology by itself did not improve education [10, 19]. Governmental programs 
aiming at the dissemination and integration of ICT while improving the educational and social conditions include-Mexico, ProNap online (a website to keep teachers updated), Red Escolar (a school network of educational computer science), and EduSat (education through television, based on satellite technology) [18, 20].

Importantly, the efforts in Mexico to implement the national ICT education objectives resulted in the creation of a new curriculum [21] that is based on the ISTE NETS standards [5], also used in many schools in the U.S., and includes the transversal teaching of ICT both on elementary and secondary school levels. Those standards strive to develop skills in six fields, including those of "Creativity and Innovation" and "Critical thinking, problem solving and decision taking" [21]. In these two fields, computer science activities are particularly relevant for student skills development. According to the Educational Studies Center, however, the new curriculum does not translate into specific activities enabling transversality and the actual development of abilities [19]. This major shortcoming and the many remaining challenges as yet unsolved by existing programs result in the ongoing demand for computer science education activities that can be integrated into school curricula in order to develop high level abilities in the above mentioned fields. The pedagogical ideas and classroom activities of the U.S. Scalable Game Design project were considered promising candidates for meeting these demands because they are aligned with the ISTE NETS standards and have an established track record regarding their integration in school curricula [16].

Scalable Game Design (SGD) has successfully broadened computer science participation in the United States through engaging teachers and students in game and simulation design [16]. This research builds upon previous SGD work on engaging students in computers science education with reference to cyberlearning [15] and computational thinking [23]. This engagement is based on a theory entitled the Zones of Proximal Flow [2]. This theory combines Vygotsky's Zone of Proximal Development [22] with Csíkszentmihályi's theories on Flow [3] and is aimed at keeping students motivated through simulation and game design. Part of this strategy includes providing tools for cyberlearning, online programming environments, real time classroom management [1], implementation and evaluation of computational thinking [16], teacher professional development [16], and providing resources supporting low threshold/high ceiling curricula $[2,7]$. So far, the SGD project has helped over 20,000 students in the U.S. create their first games and simulations [16]. Furthermore, SGD successfully launched the Swiss Computer Science Education Week (CS Ed Week) activity in 2014 [4, 17], extending its scope to Europe.

The acknowledgement of SGD's track record of success in the US and beyond resulted in the SGD Mexico project, which is a partnership between the U.S. based SGD project on the one hand and Tecnológico de Monterrey (ITESM) and Instituto de Innovación y Transferencia de Tecnología de Nuevo León (I2T2). The aim of the 2015 SGD Mexico project is to help reinvent and invigorate computer science education in Nuevo León, Mexico, through innovative, engaging, and motivating game design programming and computational thinking activities proven to be effective through research. In 2015, SGD Mexico was awarded a Google RISE Partnership Award aimed at broadening participation in Computer Science and increasing access to Computer Science Education in Mexico. Due to the interest generated about SGD in Mexico, the team was also awarded research funds from the Mexican National Council on Science and Technology (CONACyT) to add a research data collection component to the activities, to measure student motivation and learning.

One of the goals of the SGD Mexico project was to launch CS Ed Week in Mexico with a small pilot in 2014 using an accessible online activity tailored to the needs of Mexican students. To this end, SGD Mexico, ITESM and I2T2 worked together to develop and test a pilot study, using a modified SGD CS Ed Week activity, in Nuevo León, Mexico, on December 7-13, 2014. This pilot was run in ITESM. The small-scale recruitment, conducted with the help of I2T2 and the Secretaría de Educación de Nuevo León, focused primarily on public schools. In the U.S., SGD has worked with hundreds of teachers and partnered with national organizations to advertise various activities. The infrastructure that exists in the U.S. to help broaden participation in computer science does not exist as deeply in Mexico. Professor Ramírez had to develop partnerships in order to recruit the greatest number of students possible. Many of the participating pilot teachers were computer science teachers that had worked with robotics programs in the past or had formerly collaborated with ITESM in coding activities, and were highly motivated to take part in this activity. Post pilot implementation in 2015 will have a larger scale recruitment strategy that in part will include a marketing, radio and social network campaign as well as recruitment from not just public schools but also direct recruitment from private schools.

The principal aim of the Mexican pilot, conducted in parallel to the full-scale 2014 U.S. and Swiss SGD CS Ed Week activities, was to get a baseline idea of the challenges that need to be overcome for a full-scale 2015 Mexican CS Ed Week rollout. Hopefully, the project challenges identified, and new strategies and resources developed, will help broaden participation in Mexico, and can be applied to broaden participation in similar international contexts and even feedback into the U.S. For example, it has been reported that English Language Learners are one of the most underrepresented groups in the U.S. in CS and STEM fields [13]. It is our hope that the multilingual resources developed for Mexico and Switzerland can transfer back to the U.S. and be integrated into a cohesive strategy helping to motivate second language learners in computer science.

Generally, CS Ed Week activities are highly scaffolded online introductions to programming. They are advertised as self-guided, with embedded tutorials [9]. The model is equivalent to providing a link to a webpage and hoping that the activity scaffolding will be sufficient to keep students engaged. However, in international contexts more thought must go into tailoring the activity for the intended target. Assumptions pertaining to the languages students understand and technology schools have access to might not be valid [8]. The international challenge for CS Ed Week activities is, in addition to motivating student-interest in computer science, that they must first be well matched to students' and teachers' environments and abilities. Although the SGD CS Ed Week activity is self-contained, novice teachers have to be supported in doing it, for example, in case something went wrong with student projects. In 2014, professors from the Mexican project attended the annual SGD Summer Institute professional development in the U.S. These professors, alongside CS student volunteers of ITESM, were present for the hour-long pilots in Monterrey public schools. Furthermore, the organizers launched a SGD Mexico website offering online support including classroom materials. ${ }^{2}$

\footnotetext{
2 http://www.csedweek.mx/
} 


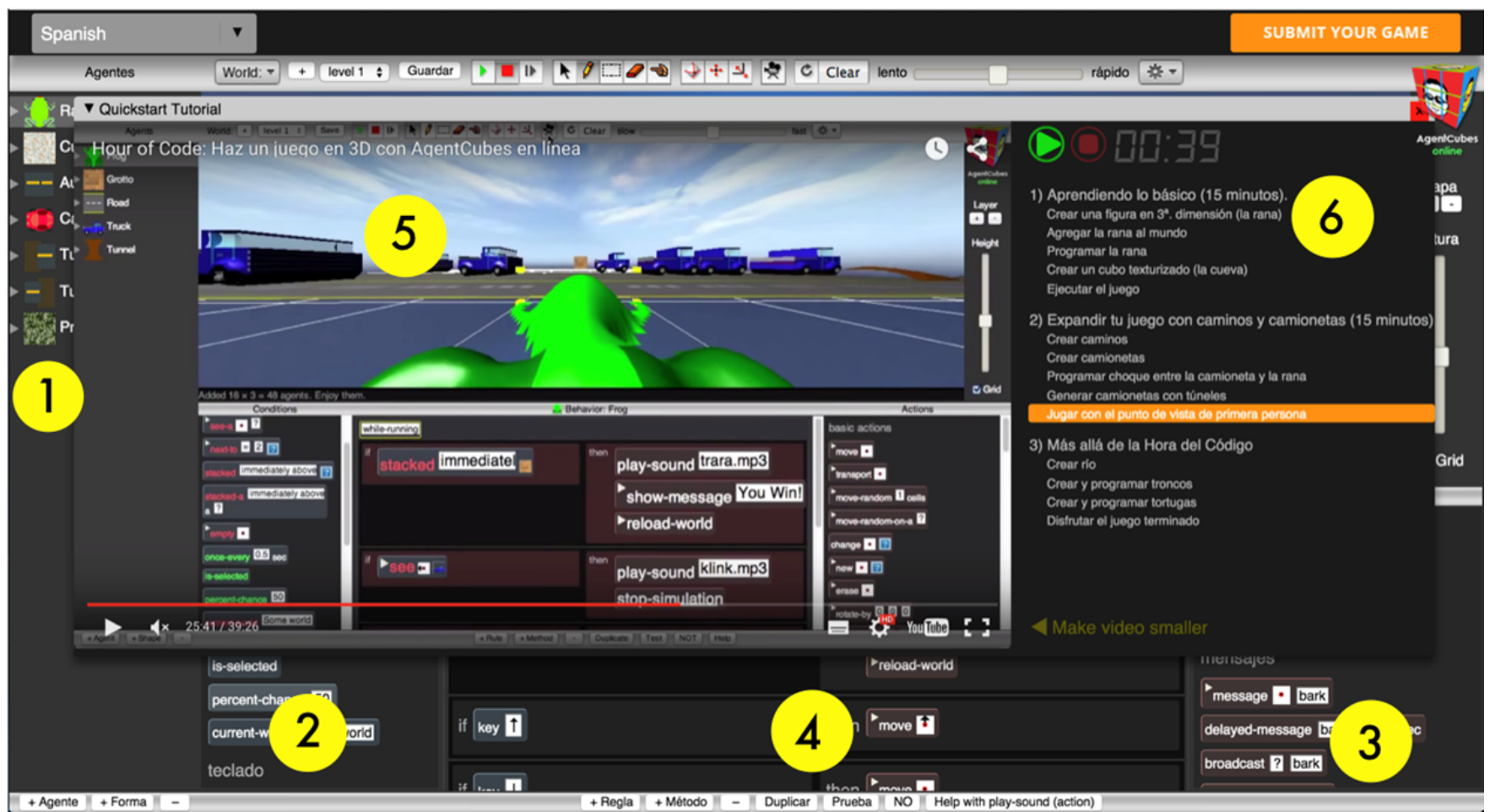

Figure 1. Scalable Game Design AgentCubes Online CS Ed Week Activity.

The idea was to provide Mexican participants with online resources such as tutorials and lesson plans, which are well established in the U.S. SGD project. Some of these electronic materials were already available during the pilots.

The aim of this Mexican CS Ed Week pilot was to identify major challenges in Nuevo León and prepare the activity for a full rollout in 2015. The hypothesis, based on discussions with our contacts in Mexico, is that resource constraints at some of the schools, especially regarding technology limitations, could result in issues that negatively affect student activity retention. The research question investigated is what are the specific factors that might affect this retention. Subsequent sections will first describe the SGD CS Ed Week activity, then outline the primary challenges in modifying the activity for Mexico, and then present initial activity retention results along with a brief discussion.

\section{The 3D FROGGER ACTIVITY}

The Scalable Game Design CS Ed Week activity is an HTML5 browser based exercise wherein users program a 3D-Frogger game inspired by the 80's classic arcade game Frogger in AgentCubes Online. ${ }^{3}$ The positive motivational aspects of the Frogger activity have already been established on the basis of experiences reported by thousands of students [16]. AgentCubes Online is a browser based visual programming tool that enables users to build their own games and simulations. The tool implements the pedagogical approach of a strong correlation between student motivation resulting from the experience of ownership and the opportunity of being creative on the one hand and learning progress on the other hand [16]. Students can create their own individual 3D-characters called "Agents" from scratch with the built-in graphics editor and select their self-made characters listed in the "Agent Gallery" (Fig. 1, label 1) to design their own virtual 3D-worlds. Users create in-game interactions between the characters by composing character behavior rules. These rules consist of programming blocks from the "Conditions"-palette (Fig. 1, label 2) and the "Actions"-palette

\footnotetext{
${ }^{3}$ http://www.csedweek.us.
}

(Fig. 1, label 3), which are assembled in the "Behavior Editor" (Fig. 1, label 4) by drag-and-drop programming. Apart from the syntactic support provided by drag-and-drop programming, the tool also offers semantic support through conversational programming, which uses graphic annotations to visualize what the program will do at any given stage and thereby facilitates the debugging of faulty code. Equipping AgentCubes Online with an embedded video tutorial in English, Spanish, German, Italian, and French (Fig. 1, label 5), the CS Ed Week activity enables students to build a complete 3D-Frogger game guided by the tutorial's step-by-step verbal and visual instructions. The video itself is supplemented by an interactive table of its contents consisting of indexed links allowing students to (re-)access instructions for each single programming step (Fig. 1, label 6). Students who follow the video tutorial will complete similar 3D-Frogger games consisting of identical rules. Figure 1 is a screenshot of this activity when the student has programmed the frog-truck collision and the tutorial shows how to switch to first-person view.

After the activity, students are not only able to play their own games and share them with others but are also given a link to their games, which allows them to return whenever they want to modify their games. (In the context of the Google RISE Partnership Award, the Mexican pilot's participants were granted AgentCubes Online licenses for one year). Hypothetically, students could return to their games at any point in time after the activity introduction to make modifications.

Conducting the CS Ed Week Mexican pilot consisted of adapting the activity to the Mexican context, which primarily involved addressing language and technology challenges. In terms of language, the whole activity had to be translated into Spanish since even Mexican students at the middle school level often have little fluency in English. The translated elements included the audio narration of the embedded video tutorial (Fig. 1, label 2) and the indexed video links allowing users to access specific instructions on how to program a given interaction in Frogger (Fig. 1, label 3). Previous experiments, in German, looked at changing the conditions and actions, in Figure 1 labels 4 and 5, to students' native language. However, it was decided that to keep 
consistency between the visual language environments, the program would instead provide a tooltip in the native language (in this case Spanish) when the cursor hovers over a given condition or action. The hope was that these changes would allow the Mexican students to understand the embedded video instruction along with the environment, including the mechanics of game creation. In terms of technology, limited Internet access was anticipated to be the main issue. As mentioned before, only $18 \%$ of the public schools at primary and secondary level have access to the Internet [9]. These circumstances are quite disadvantageous for conducting a browser based programming activity. For those cases where Internet access was not available or the bandwidth was too limited for conducting the activity online, students had to use the English desktop version of AgentCubes and were provided with the video tutorial on a USB-stick or with printed instructions.

\section{METHODOLOGY}

To assess the overall efficacy of the activity and its adaptation for use in Mexico, we used participant retention as an evaluation instrument. Retention in this case meant how long a student remained with the activity before stopping. Every time a user modifies their program for a given agent in AgentCubes Online, by adding methods, rules, conditions, and actions, an XML file corresponding to that agent's programmed behaviors is modified on the server. Analyzing all the XML files corresponding to each agent allows for an operationalization of program length akin to a lines of code metric. The complete tutorial-guided 3D-Frogger activity consists of 215 lines of code in AgentCubes Online, which we calculate by analyzing the XML files. We surmise that by looking at retention data, conclusions can be drawn on the effectiveness of the video tutorial to relay the programming activity's instructions, as well as learn about factors that may lead to students discontinuing the activity. As explained above, the CS Ed Week 3D-Frogger video tutorial provides step-by-step instructions that lead to students building identical games with the same rules and lines of code. Each step of the programming taught by the tutorial directly correlates to a known and consistent set of lines of codes in student projects. Because of the direct relationship between the steps of taught by the tutorial and the actual lines of code that students create, a project's number of lines of code correlates directly to how far a student followed the tutorial and at what point in the tutorial he or she left the activity.

In past classroom SGD observations, students usually get to a program length of around 46 or 59 within an hour. In the CS Ed Week activity these two lengths correspond to the Frog moving in all four directions, at a program length of 46 , and the win state of the game wherein the player wins if the frog jumps on a target at the end of the level, at a program length of 59.

\section{RESULTS}

Despite all these difficulties and some as yet unresolved challenges, the pilot was successfully launched. In total, 5 schools, 11 classes, and over 350 mainly middle-school students participated in the event, and every participating pilot teacher has already expressed interest in continuing participation with the 2015 activity. From those participating in the activity, we were able to gather and analyze both qualitative data, in the form of inclass observations and statements of participating students, and quantitative data, in the form of student retention through the activity. The data shows that the adaptation of the activity to the Mexican context had promising results. Qualitative data was gathered from all teachers and their students. However, due to some schools' lack of the required bandwidth of the Internet access, many students had to conduct the activity using the desktop version of AgentCubes. Therefore we only gathered and analyzed quantitative data in the form of XML files from those 109 students who could do the activity using AgentCubes Online. On the basis of these data, we employed retention as an instrument to assess the efficacy of the activity.

\subsection{In-Class Observations}

In-class observations from the Mexican CS Ed Week activity indicate that, despite of language and technology related challenges, students enjoyed the activity and wanted to continue. Teachers reported that students were very motivated and attentive while performing the activity. Some students commented that they should have more activities like this in their computer lab. At the end of the activity many students asked for the link so they could continue their work at a later time. The students seemed to prefer doing the activity by themselves or in pairs, which was found to be more efficient than following class instructions as a group. Finally, students worked at different rates; most students were able to work effectively for an hour.

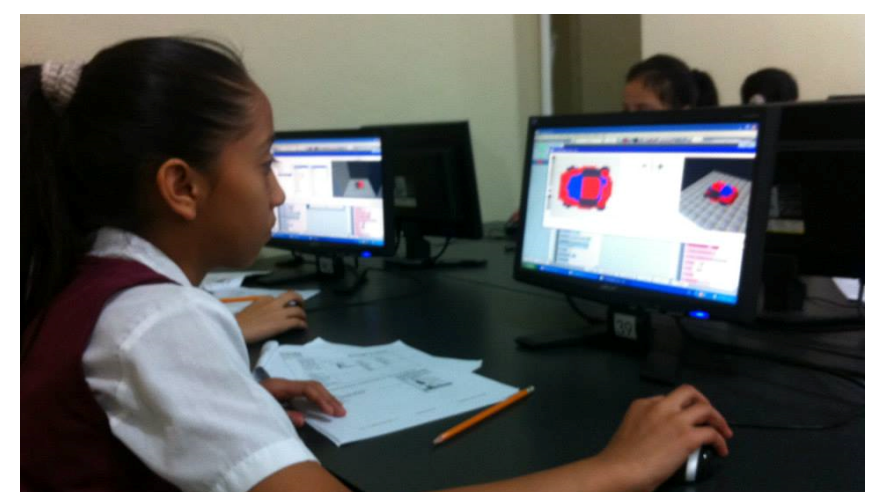

Figure 2. A Girl drawing a Car "Agent" during the Mexican Pilot using the Desktop Version of AgentCubes and following Printed Out Instructions.

As anticipated, the main challenges encountered during the activity were related to language and technology. Regarding language students were confused when the narration of the video tutorial occasionally used Spanish words to refer to parts of the programming environment that are in English. Some students had to use English desktop version leading to more time between steps and greater dependence on the in-class support team.

Technology challenges were much more extensive. Bandwidth constraints limited many students from properly loading the embedded video tutorial in their browsers while doing the activity in AgentCubes online. Some schools maintained a single YouTube connection to screen the tutorial for all students. In case of even greater bandwidth limitations, students either received memory sticks containing the video tutorial or had to use written instructions. At two of the five schools bandwidth limitations were so dire that students could not even do the activity in AgentCubes online and had to use the software's desktop version instead. As mentioned before, from these students using the desktop version of AgentCubes, we could not gather quantitative retention data. In terms of hardware, some computers were outdated running Windows XP with 512 of RAM, which adversely affected students using the offline desktop version of AgentCubes. The main software issue was that some computers only had Internet Explorer installed. This caused an AgentCubes online error due to writing invalid XML (recommended browsers 
include Chrome, Firefox and Safari with WebGL enabled). Once the error was encountered students could not continue their project on AgentCubes online.

These observations and experiences of the pilot study are of great value because they identified the above challenges to the activity, which we can attempt to eliminate with the full-scale 2015 rollout. Examples could include well-prepared contingency plans if bandwidth issues are encountered, making sure computers have the correct software, and updating the activity narration.

\subsection{Retention}

The first-time data collected in the Mexican pilot resembles data collected in the 2014 CS Ed Week activities in the United States and Switzerland. Figure 4 shows the student retention through every program length in 3D-Frogger (maximum program length of 215) for the SGD CS Ed Week Activity in Mexico, the U.S. and Switzerland. We start at $100 \%$ at the program length of 1 and, as we increase, we lose students as their numbers drop off at each program length greater than 1. Estimating these points could show student deviation from student engagement. Figure 3 shows that the data from all three main participating countries in the activity, i.e. U.S., Switzerland $(\mathrm{CH})$, and Mexico (MX), fit a negative exponential trend well.

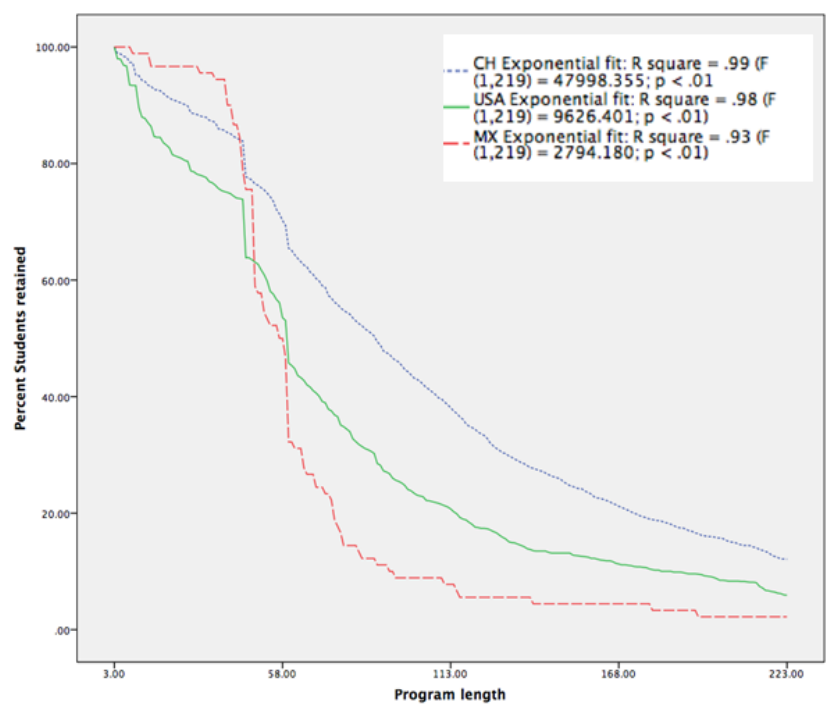

Figure 3. Percentage of Retained CS Ed Week Activity Students by Country.

The nature of student retention in all three countries followed the same general trend, regardless of language or environment. The negative exponential fit also implies that in every country the activity retained a higher percentage of students at each step as the activity went on. These results are promising for the Mexican pilot. Figure 4 depicts the mean program length of each country with associated error bars. According to ANOVA, countries differ with reference to the mean game complexity $(\mathrm{F}(2,4768)=65.932$; $\mathrm{p}<.01$ ). Post hoc tests (Scheffé) reveal that the only significant differences are between Switzerland $(M=95.149)$ and the US $(\mathrm{M}=60.507)$ as well as between Switzerland and Mexico $(M=50.890)$. No significant differences were found between the more established U.S. activity and the Mexican pilot. In general, the comparison between U.S., Mexico and Switzerland may primarily reflect shortcoming regarding hardware and bandwidth, which assumedly led to generally shorter program lengths. As shown by figure 3 , clear points of inflection occur at program lengths of 45 and 59 independent of the country. In prior classroom observations, students creating 3D-Frogger got to a program length of about 46 to 59 in the first hour, the mean program length of around 50 for Mexican students, and 59 in the

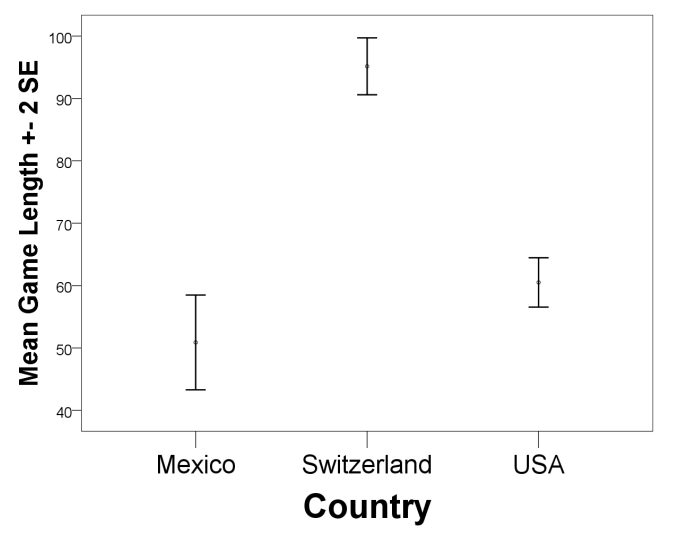

Figure 4. Mean Game Program Length by Country with Error Bars.

U.S students, is right within this expected range.

Despite the challenges encountered, students in the Mexican pilot study using the modified AgentCubes online activity performed on par with U.S. students. The Switzerland games produced were significantly longer than those of both Mexico and the U.S. in terms of lines of code.

\section{DISCUSSION}

As suggested by the mean game length with error bars, the retention in Mexico was not significantly different statistically from the retention in the U.S. However, the distribution of the Mexican retention is wider and includes more students creating only relatively small programs. In Figure 3, this can be seen in the relative low Mexican retention after the 59 lines of code point. The 59 lines of code point coincides with the "win state is detected" activity checkpoint, which most students reach after about one hour. This pronounced retention drop suggests that most of the participating schools only spent one hour. Similarly, the retention of students in the USA or Switzerland dropped less because they continued beyond one hour of coding in school or even at home. After one hour, students are encouraged to submit their games. When they do, they receive an email including a link to their game allowing them to continue working on the project. Due to their generally more limited computer access at home, however, Mexican students were far less likely to continue with their game projects than Swiss and U.S. students. The really high retention beyond the first hour in Switzerland may be due to the timing of the activity [4]. During CS Ed Week, many Swiss schools have so-called project weeks where teachers are free to dedicate multiple school sessions to special projects. Furthermore, the fact that games of Swiss students were significantly longer than those of U.S. and Mexican students could be due to additional support provided to the Swiss activity including a 10 hour a day phone-in help line and email support consisting of a staff of 3 full-time workers during CS Ed Week [4]. This might be something that could be extended to the Mexican and U.S. activities to better deal with technical issues that may come up during the activity.

In spite of the relatively low retention beyond one hour in Mexico, the number of students retained in the first hour is remarkably high, exceeding the Swiss and U.S. retention. This is difficult to 
explain because it appears to contradict anticipated impacts of infrastructure and language challenges. The Mexican, U.S., and Swiss retention need to be compared carefully as the number of participants in Mexico during the pilot was almost two orders of magnitudes smaller $(\mathrm{n}($ Mexico $)=109)$. The number of participants alone is not likely to have caused this effect but perhaps the nature of the project in Mexico still being in a pilot stage did. Possibly, pilot schools in Mexico were recruited more strategically, resulting in higher levels of commitment among teachers and students. The fact that ITESM computer science students were present during the activity to support both teachers and students may be another reason for the high number of retained students within the first hour. Additionally, the bandwidth problems discussed earlier resulted in some schools playing the tutorial video theater style in front of students. In contrast to each student playing the video at his or her own speed this lockstep approach may have resulted in high retention by making it difficult for student to drop out.

\section{CONCLUSION}

Despite Mexico being a developing country, with very little infiltration of Internet connectivity and computer science education into public schools, the pilot was able to broaden participation in computer science in Mexico. Additionally, the students produced games of similar complexity like those of the U.S. students using the AgentCubes Online activity, and teachers and students expressed interest in pursuing further activities in the future. The results of this pilot bode well for the upcoming Google RISE Partnership and full rollout of the 2015 Mexican CS Ed Week. The high level of the students' interest and engagement during the 2014 CS Ed Week pilot was a catalyst for an entire state to get excited about coding and to commit to the goal of giving all students in Mexico more access to CS activities. By including a more comprehensive teacher professional development, and the development of the program Chic@s Code, which is especially aimed at broadening Latina participation in computer science, we can build upon this pilot experience to motivate the greatest number of students possible, engaging Mexico in computer science through CS Ed Week and beyond.

\section{ACKNOWLEDGMENTS}

This work is supported by the Google K-12 Education Outreach Fund Tides Foundation (grant \#TFR14-03105), the National Science Foundation (grants \#1138526 and \#1312129), and the Hasler Foundation. Any opinions, findings, and conclusions or recommendations expressed in this material are those of the authors and do not necessarily reflect the views of the NSF We thank the ITESM; the I2T2 de Nuevo León; and the Secretaría de Educación de Nuevo León for logisitic help; and the Instituto Tecnológico y de Estudios Superiores de Monterrey, Computer Science's student association, AgentSheets Inc., the Computational Thinking Foundation and CONACyT for funding.

\section{REFERENCES}

[1] Basawapatna, A. R., Repenning, A., and Koh, K. H. 2015. Closing The Cyberlearning Loop: Enabling Teachers To Formatively Assess Student Programming Projects. In Proc. SIGCSE '15, 12-17.

[2] Basawapatna, A. R., Repenning, et al., 2013. The Zones of Proximal Flow: Guiding Students through a Space of Computational Thinking Skills and Challenges. In Proc. ICER '13, 67-74.
[3] Csíkszentmihályi, M. 1977. Beyond Boredom and Anxiety. San Francisco: Jossey-Bass.

[4] Escherle, N. A., Assaf, D., Basawapatna, A. R., et al. 2015. Launching Swiss Computer Science Education Week. In Proc. WIPSCE '15, 11-16.

[5] Instituto Nacional de Estadística y Geografía (INEGI), 2015. Cuéntame: Población de México. http://cuentame. inegi.org.mx/poblacion/asistencia.aspx?tema=P.

[6] ISTE. 2015. ISTE Standards for Students. http://www.iste. org/standards/ISTE-standards/standards-for-students.

[7] Koh, K. H, Nickerson H., Basawapatna, A. R., and Repenning, A., 2014. Early Validation of Computational Thinking Pattern Analysis. ACM (June 2014). 213-218.

[8] Kraemer, K. L., Dedrick, J., and Sharma, P. 2009. One Laptop Per Child: Vision vs. Reality. In Commun. ACM 52, 6 (June 2009). 66-73.

[9] Kumar, D. 2014. Digital Playgrounds for Early Computing Education. In ACM Inroads 5, 1 (Mar. 2014). 20-21.

[10] Martínez, N. 2012. En escuelas de México, amplia brecha digital. El Universal, martes 4 de septiembre, 2012.

[11] National Center for Education Statistics (NCES). 2001. Internet Access in U.S. Public Schools and Classrooms: 1994-2000. http://nces.ed.gov/pubs2001/2001071.pdf.

[12] National Center for Education Statistics (NCES). 2014. Percentage of high school dropouts among persons 16 through 24 years old (status dropout rate), by sex and race/ethnicity: Selected years, 1960 through 2013. http://nces.ed.gov/ programs/digest/d14/tables/dt14_219.70.asp.

[13] NSF Report. 2013. Women, Minorities, and Persons with Disabilities in Science and Engineering: 2013.

[14] OECD. 2012. Education at a Glance: OECD Indicators. Mexico. http://www.oecd.org/mexico/EAG2012\%20-\%20 Country\%20note $\% 20-\% 20$ Mexico.pdf.

[15] Pea, R. D. 2007. A Time for Collective Intelligence and Action: Grand Challenge Problems for Cyberlearning. In NSF Cyberinfrastructure Team Workshop, Washington, D.C.

[16] Repenning, A., Webb, D. C., Koh, K. H., Nickerson H., Miller, S. B., Brand, C., et al. 2015. Scalable Game Design: A Strategy to Bring Systemic Computer Science Education to Schools through Game Design and Simulation Creation. In TOCE '15, 2. 1-31.

[17] Repenning, A., Assaf, D., Basawapatna, A.R., et al. 2016. The Retention of Flow. In Proc. SIGCSE ' 16.

[18] Romero, J. L. R. 2006. Las Tecnologías de la Información y la Comunicación en la Educación en Cuatro Países Latinoamericanos. In Revista Mexicana De Investigación Educativa, 11, 28. 61-90.

[19] Santiago, D. 2015. Dejan 28 mil escuela en NL. In El Norte Sunday August 23.

[20] Santibanez, L., Vernez, G. and Razquin, P. 2005. Education in Mexico: Challenges and Opportunities. Santa Monica, CA: RAND Corporation. http://www.rand.org/pubs/ documented_briefings/DB480.html.

[21] Secretaría de Educación Pública (SEP). 2012. Reforma Integral de la Educación Básica. http://basica.sep.gob.mx/tiem pocompleto/pdf/memorias2012/articulacion_educ_bas.pdf.

[22] Vygotsky, L.S. 1980. Mind in Society: The Development of Higher Psychological Processes. Harvard University Press.

[23] Wing, J. M. 2006. Computational Thinking. In Commun. ACM 49, 3. 33-35. 